\title{
Casca de arroz carbonizada como substrato alternativo na propagação por estaquia de ixora (ixora coccínea)
}

A ixora (Ixora coccínea) é um arbusto muito utilizado na floricultura e se destaca pelo seu uso como bordaduras, cercas vivas entre outros. $O$ substrato comercial, embora apresente qualidade indispensável para produção de mudas, torna o custo final bem mais elevado e uma forma de superar essa limitação é a utilização de substrato regional ou alternativo. Visto que o mercado de flores tem crescido no ramo paisagístico do agronegócio, o presente trabalho teve como objetivo avaliar a utilização da palha de arroz carbonizada como substrato para a produção de mudas de ixora via estaquia. Adotou-se delineamento inteiramente casualizado, com cinco tratamentos e quatro repetições referente a utilização de substrato a base de casca de arroz carbonizada (CAC). Para todos os tratamentos, realizou-se a formulação de substratos (S) nas seguintes proporções: S1- 100\% de areia; S2- $20 \%$ de CAC + 80\% de areia; S3- $40 \%$ de CAC + 60\% de areia; S4- $60 \%$ de CAC + 40\% de areia; S5- $80 \%$ de CAC $+20 \%$ de areia. Os dados foram submetidos à análise de variância pelo teste ' $F$ ', para diagnóstico de efeito significativo e os tratamentos comparados entre si pelo teste de Duncan a $5 \%$ de probabilidade. Os substratos de casca de arroz carbonizada apresentaram resultados satisfatórios na propagação vegetativa das estacas de ixora. Recomenda-se, para propagação das estacas de ixora, a utilização de $80 \%$ de casca de arroz carbonizada acrescida a $20 \%$ de areia, como substrato alternativo para produção de mudas de ixora.

\section{Carbonized rice husk as alternative substrate in the propagation of ixora cuttings (ixora coccínea)}

Ixora (Ixora coccínea) is a shrub that is widely used in floriculture and stands out for its use as borders, hedges, among others. The commercial substrate, althoug presenting indispensable quality for seedling production, makes the final cost much higher and a way to overcome this limitation is the use of regional or alternative substrate. Since the flower market has grown within agribusiness, this study aimed to evaluate the use of carbonized rice husk as a substrate to produce ixora seedlings via cuttings. A completely randomized design was adopted, with five treatments and four repetitions regarding the use of substrate based on carbonized rice husks (CRH). For all treatments, substrates (S) were formulated with the following proportions: S1- $100 \%$ sand; S2- $20 \% \mathrm{CRH}+80 \%$ sand; S3- $40 \%$ CRH + 60\% sand; $S 4-60 \% \mathrm{CRH}+40 \%$ sand; $S 5-80 \% \mathrm{CRH}+20 \%$ sand. The data was analyzed for variance by ' $\mathrm{F}$ ' test. To diagnosis significant effect and the treatments compared to each other the Duncan test at $5 \%$ probability was used. The carbonized rice husk substrates showed satisfactory results for vegetative propagation of ixora cuttings. For the propagation of ixora cuttings, the use of $80 \%$ carbonized rice husk plus $20 \%$ sand is recommended as an alternative substrate to produce ixora seedlings.

Keywords: Floriculture; Landscaping; Sustainability; Economic resource.

Topic: Ciências do Solo

Reviewed anonymously in the process of blind peer
Received: 02/02/2021

Approved: 25/02/2021
Ana Paula de Almeida Sousa (iD Universidade Federal do Maranhão, Brasil http://lattes.cnpq.br/6553307786330116 http://orcid.org/0000-0002-1790-7114 anasousa_almeida@hotmail.com

Samuel Ferreira Pontes (D)

Universidade Federal do Piaú, Brasil http://lattes.cnpq.br/5268797301695901 http://orcid.org/0000-0001-7696-3629 samuellpontes@outlook.com

Raissa Rachel Salustriano da Silva Matos (iD) Universidade Federal do Maranhão, Brasil http://lattes.cnpq.br/0720581765268326 http://orcid.org/0000-0002-8908-2297 raissasalustriano@yahoo.com.br
Myllenna da Silva Santana (iD)

Universidade Federal do Maranhão, Brasil http://lattes.cnpq.br/5478258168962551 http://orcid.org/0000-0003-3633-112X myllennasantan@hotmail.com

Deucleiton Jardim Amorim (iD) Universidade Estadual Paulista “Júlio de Mesquita Filho", Brasil

http://lattes.cnpq.br/3121121800829042 http://orcid.org/0000-0002-6789-0760 deucleitonamorim@hotmail.com

Carlos Alberto Araújo Costa (iD

Universidade Federal do Maranhão, Brasil http://attes cnpa br/2384531482653796 http://lattes.cnpq.br/2384531482653796 carlosaraujo961010@gmail.com

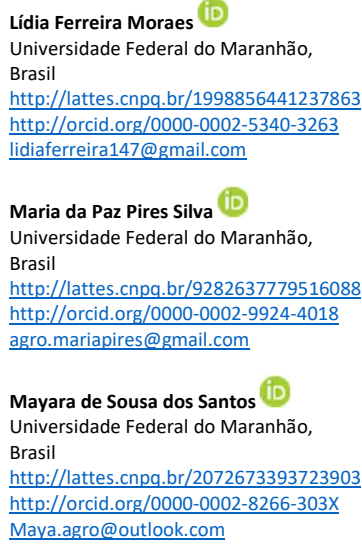

\section{Referencing this:}

SOUSA, A. P. A.; PONTES, S. F.; MATOS, R. R. S. S.; SANTANA, M. S. AMORIM, D. J.; COSTA, C. A. A.; MORAES, L. F.; SILVA, M. P. P.; SANTOS, M. S.; TAVARES FILHO, G. S.. Casca de arroz carbonizada como substrato alternativo na propagação por estaquia de ixora (ixora coccínea). Revista Ibero Americana de Ciências Ambientais, v.12, n.2, p.19-26, 2021. DOI: http://doi.org/10.6008/CBPC21796858.2021 .002 .0003
Gilberto Saraiva Tavares Filho (iD Universidade Federal do Vale do São Francisco, Brasil gilfilho753@hotmail.com http://lattes.cnpq.br/0502160177022205 http://orcid.org/0000-0003-3360-4022

DOI: 10.6008/CBPC2179-6858.2021.002.0003 


\section{INTRODUÇÃO}

A floricultura encontra-se como um dos mais novos empreendimentos do agronegócio brasileiro, ela é a soma de atividades produtivas e comerciais cujas finalidades são ornamentais. Apesar da crise que o Brasil se encontra, o setor de flores tem crescido de forma surpreendente. 'Foram faturados R\$ 5,7 bilhões em 2014, R\$ 6,2 bi em 2015, R\$ 6,65 bi em 2016 e, para o ano de 2017, o crescimento em todo o país foi de 9\% com faturamento de R\$̦ 7,2 bilhões'.

No ramo da floricultura, a ixora (Ixora coccínea), é bastante utilizada como cercas vivas e de forma individual (BELLÉ, 2013). Essa pertence às espécies de plantas ornamentais e arbustivas, na qual é empregada em projetos paisagísticos. Sua floração mantém-se ao longo do ano, diminuindo no inverno e, intensificando na primavera, o que resulta em jardins floridos e exuberantes (STENICO, 2013).

A técnica utilizada para sua propagação é feita via estaquia. A multiplicação de plantas por estacas tem como objetivo a formação de várias mudas semelhantes à matriz, sendo um processo simples e econômico (FELICIANA et al., 2017). Contudo, o conhecimento desse método ainda é incipiente no sentido de enquadrá-lo como uma técnica eficaz para produção de mudas em escala comercial.

De acordo com Koyama et al. (2014), existem fatores que interferem no enraizamento da estaca, tais como a associação de um substrato de qualidade e o estado nutricional da planta. Logo para obter-se mudas de qualidade, o substrato deve conter propriedades físicas e químicas permitindo um bom desenvolvimento do sistema radicular e consequentemente da parte aérea (TRIGUEIRO et al. 2014).

O substrato comercial, embora apresente qualidade indispensável para produção de mudas, torna o custo final bem mais elevado e uma forma de superar essa limitação é a utilização de substrato regional ou alternativo, pois estes substratos também podem apresentar a mesma eficiência quanto o comercial, além disso, proporciona uma renda maior para o agricultor.

Uma alternativa interessante de substrato é a utilização da palha de arroz carbonizada, essa possui características que permitem boa aeração, drenagem, influencia na troca de ar na base das raízes, sendo também indicada para a germinação de sementes e enraizamento de estacas (SOUSA, 1993). Castro et al. (2016) testaram palha de arroz carbonizada como substrato na produção de mudas de Enterolobium contortisiliquum obtendo plantas que ao serem plantadas em campo, proporcionaram aumentos significativos.

Nesse sentido, visto que o mercado de flores tem crescido no ramo paisagístico do agronegócio, o presente trabalho teve como objetivo avaliar a utilização da palha de arroz carbonizada como substrato para a produção de mudas de ixora via estaquia.

\section{MATERIAIS E MÉTODOS}

\section{Área de estudo}

O experimento foi desenvolvido no período de março a julho de 2019, no Centro de Ciências Agrárias e Ambientais (CCAA), da Universidade Federal do Maranhão (UFMA) (Figura 1), em casa de vegetação (Figura 
2), localizada no município de Chapadinha - MA, localizado a 03 $44^{\prime} 30^{\prime \prime}$ de latitude Sul, 43 21' 37”, de longitude Oeste. De acordo com a classificação de Kôppen, o clima do município se enquadra como Aw, quente e úmido, com altitude média de $107 \mathrm{~m}$, temperatura média anual de $27^{\circ} \mathrm{C}$ e precipitação média anual de $1.835 \mathrm{~mm}$, com períodos de chuva entre os meses de janeiro e junho e de seca de julho a dezembro (PASSOS et al., 2016).

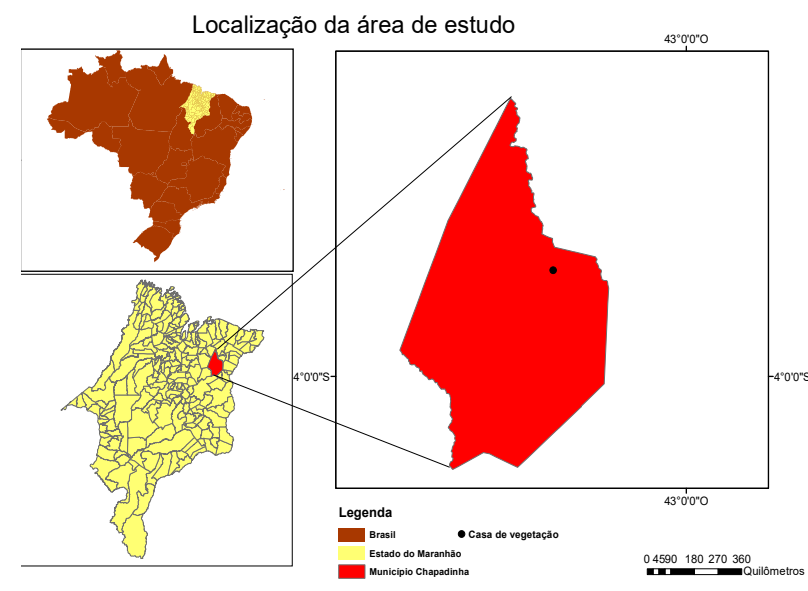

Figura 1: Localização da casa de vegetação no Centro de Ciências Agrárias e Ambientais (CCAA) da Universidade Federal do Maranhão (UFMA).

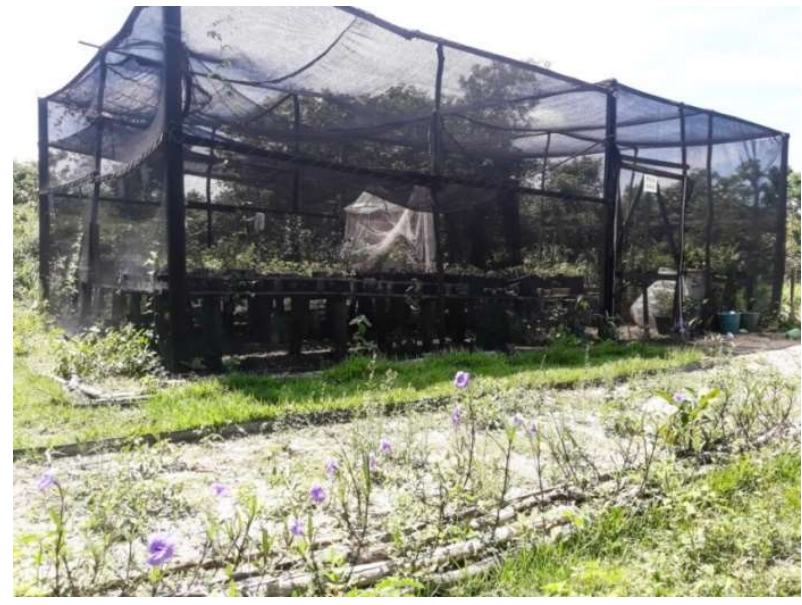

Figura 2: Casa de vegetação experimental localizada no Centro de Ciências Agrárias e Ambientais (CCAA) da Universidade Federal do Maranhão (UFMA).

\section{Delineamento experimental}

Adotou-se o delineamento experimental inteiramente casualizado, com cinco tratamentos, quatro repetições e uma planta para cada repetição, sendo utilizado estacas de ixora acondicionadas em sacos de polietileno com substrato a base de casca de arroz carbonizada (CAC). Para todos os tratamentos, realizouse a formulação de substratos (S) nas seguintes proporções: S1- $100 \%$ de areia; S2- $20 \%$ de CAC + $80 \%$ de areia; S3- $40 \%$ de CAC $+60 \%$ de areia; $54-60 \%$ de CAC $+40 \%$ de areia; $55-80 \%$ de CAC $+20 \%$ de areia.

\section{Carbonização e preparação de substrato}

Tabela 1: Valores de $\mathrm{pH}$, condutividade elétrica $(\mathrm{CE})$ e teores totais de nitrogênio $(\mathrm{N})$, fósforo $(\mathrm{P})$, potássio $(\mathrm{K})$, cálcio (Ca), magnésio (Mg) e enxofre (S), dos substratos a base de casca de arroz carbonizada (CAC).

\begin{tabular}{|c|c|c|c|c|c|c|c|c|}
\hline Substratos & $\mathrm{pH}$ & $\begin{array}{l}\text { CE } \\
\mathrm{dS} \mathrm{m}^{-1}\end{array}$ & $\begin{array}{l}\mathrm{N} \\
\mathrm{g} \mathrm{kg}^{-1}\end{array}$ & $\begin{array}{l}\mathrm{P} \\
\mathrm{mg} \mathrm{kg}^{-1}\end{array}$ & K & $\begin{array}{c}\mathrm{Ca} \\
\mathrm{cmolc} \mathrm{kg}^{-1}\end{array}$ & $\mathrm{Mg}$ & $S$ \\
\hline S1 & 5,06 & 0,10 & 0,63 & 1,3 & 0,07 & 0,80 & 0,30 & 1,5 \\
\hline S2 & 5,84 & 1,64 & 9,072 & 1,62 & 5,37 & 5,04 & 10,98 & 22,1 \\
\hline S3 & 6,94 & 1,96 & 10,08 & 1,80 & 5,97 & 5,60 & 12,20 & 24,6 \\
\hline S4 & 7,90 & 6,13 & 7,00 & 3,06 & 15,97 & 7,40 & 18,20 & 42,3 \\
\hline S5 & 4,88 & 0,61 & 1,23 & 1,4 & 0,67 & 1,60 & 1,00 & 3,8 \\
\hline
\end{tabular}

S1 - 100\% areia; S2 - 20\% CAC + 80\% areia; S3 - 40\% CAC + 60\% areia; S4- 60\% CAC + 40\% areia; S5 - 80\% CAC + $20 \%$ areia.

Para a carbonização da palha de arroz utilizou-se um carbonizador alternativo, em seguida o substrato foi misturado e homogeneizado com a areia, de acordo com a proporção de cada tratamento. As estacas foram coletadas de plantas matrizes sadias, com comprimento padronizado de $10 \mathrm{~cm}$. Em seguida foram plantadas em sacos de polietileno com dimensões $12 \times 20 \mathrm{~cm}$, com irrigação duas vezes ao dia nos horários de oito horas e dezessete horas. Previamente, a montagem do experimento, realizou-se a análise 
química referente a cada proporção de substrato (Tabela 1).

\section{Parâmetros vegetais analisados}

Após 100 dias em casa de vegetação as mudas foram coletadas e encaminhadas para o laboratório, para avaliação das seguintes variáveis: número de folhas (NF): obtidas pela contagem manual de folhas totalmente expandidas; área foliar (AF) $\left(\mathrm{cm}^{2}\right)$ : mensurada por meio do programa computacional ImajeJ ; diâmetro do broto (DB) $(\mathrm{mm})$ e diâmetro do caule (DC) $(\mathrm{mm})$ : obtidos por meio de um paquímetro digital; comprimento radicular (CR) $(\mathrm{cm})$ : obtido por meio da utilização de uma régua; volume radicular $(\mathrm{VR})\left(\mathrm{cm}^{3}\right)$ : aferido segundo a metodologia descrita por Basso (1999); massa fresca da parte aérea (MFPA) (g) e massa fresca do sistema radicular (MFSR) (g): pesadas por meio da utilização de uma balança semi-analítica; massa seca da parte aérea (MSPA) (g) e massa seca do sistema radicular (MSSR) (g): obtidas pelo método da secagem em estufa com circulação forçada de ar à temperatura de 65 ㄷ por 72 horas e pesadas em balança semi-analítica; e índice de qualidade de Dickson (IQD) - estimado pela fórmula descrita por Dickson et al. (1960), como demonstra a equação reformulada abaixo.

$$
\mathrm{IQD}=\frac{\mathrm{MST}(\mathrm{g})}{\mathrm{DB}(\mathrm{cm}) / \mathrm{CB}(\mathrm{cm})+\mathrm{MSPA}(\mathrm{g}) / \operatorname{MSR}(\mathrm{g})}
$$

Em que: MST: massa seca total; CB: comprimento do broto; DB: diâmetro do broto; MSPA: massa seca da parte aérea e MSR: massa seca radicular.

\section{Análise de dados}

Os dados foram submetidos à análise de variância pelo teste " $F$ ", para diagnóstico de efeito significativo, e os tratamentos comparados entre si pelo teste de Duncan a 5\% de probabilidade, através do programa computacional Infostat ${ }^{\circ}$ (DI RIENZO et al., 2011).

\section{RESULTADOS}

Houve efeito dos diferentes substratos estudados sobre o número de folhas, área foliar, comprimento radicular, volume radicular, massa fresca do sistema radicular, massa seca total e índice de qualidade de Dickson, em contrapartida não houve diferença significativa das diferentes proporções de casca de arroz carbonizada para as variáveis diâmetro do broto, comprimento do broto, massa fresca da parte aérea, massa seca da parte aérea e massa seca do sistema radicular.

Tabela 2: Resumo da análise de variância do número de folhas (NF), área foliar (AF), diâmetro do broto (DB), comprimento do broto (CB), comprimento radicular (CR) e volume radicular (VR), de mudas de ixora, em função das diferentes proporções de substratos.

\begin{tabular}{lllllll}
\hline Substratos & NF & AF & DB & CB & CR & VR \\
& ------- & $---\mathrm{cm}^{2}---$ & $---m m$--- & ---cm--- & ---cm--- \\
\hline S1 & $12,50 \mathrm{c}$ & $3,40 \mathrm{~b}$ & $1,72 \mathrm{a}$ & $0,70 \mathrm{a}$ & $8,28 \mathrm{~b}$ & $1,25 \mathrm{~b}$ \\
S2 & $14,25 \mathrm{c}$ & $3,27 \mathrm{~b}$ & $1,83 \mathrm{a}$ & $0,80 \mathrm{a}$ & $5,63 \mathrm{~b}$ & $1,33 \mathrm{~b}$ \\
S3 & $16,13 \mathrm{bc}$ & $3,68 \mathrm{ab}$ & $1,95 \mathrm{a}$ & $1,03 \mathrm{a}$ & $8,00 \mathrm{~b}$ & $1,20 \mathrm{~b}$ \\
S4 & $26,13 \mathrm{ab}$ & $3,27 \mathrm{~b}$ & $2,40 \mathrm{a}$ & $0,55 \mathrm{a}$ & $7,55 \mathrm{~b}$ & $1,33 \mathrm{~b}$ \\
S5 & $30,38 \mathrm{a}$ & $5,50 \mathrm{a}$ & $1,85 \mathrm{a}$ & $0,78 \mathrm{a}$ & $12,63 \mathrm{a}$ & $1,63 \mathrm{a}$ \\
CV (\%) & 32,70 & 32,01 & 26,95 & 57,24 & 24,32 \\
\hline
\end{tabular}

Médias seguidas de letras iguais não diferem entre si pelo teste Duncan à 5\% de significância. S - Substratos; S1 - 100\% 
areia; S2 - 20\% CAC; S3 - 40\% CAC; S4 - 60\% CAC; S5 - 80\% CAC + 20\% areia; CV: coeficiente de variação; *: Significativo ao nível de $5 \%$ de probabilidade, pelo teste $\mathrm{F}$; ns: não significativo.

A variável número de folhas apresentou efeito significativo com rendimento de 30,38, na utilização do substrato S5 (80\% de CAC + $20 \%$ de areia), superior em $143,0 \%$ quando comparado com o substrato de menor concentração de casca de arroz carbonizada (S1) (Tabela 2).

Semelhantemente a variável NF, a área foliar apresentou maior média $\left(5,50 \mathrm{~cm}^{2}\right)$, com a utilização do S5, proporcionando um incremento de aproximadamente 60\% quando comparado aos substratos de menor proporção de casca de arroz carbonizada (S1 e S2). As variáveis diâmetro do broto e comprimento do broto apresentaram a mesma resposta em relação à utilização dos diferentes substratos, ou seja, não obtiveram efeitos significativos em relação a utilização de CAC.

As mudas de ixora apresentaram maior comprimento radicular $(12,63 \mathrm{~cm})$ com a utilização do substrato S5 ( $80 \%$ de CAC + $20 \%$ de areia) quando comparados aos demais tratamentos, sendo que os demais tratamentos não diferiram entre si. Para a variável volume radicular, o substrato S5 $\left(1,63 \mathrm{~cm}^{3}\right)$, se sobressaiu em relação as demais proporções de casca de arroz carbonizada, com um aumento de aproximadamente $32 \%$ quando comparado aos outros substratos.

Tabela 3: Resumo da análise de variância da massa fresca parte aérea (MFPA), massa fresca do sistema radicular (MFSR), massa seca parte aérea (MSPA), massa seca do sistema radicular (MSSR), massa seca total e Índice de Qualidade de Dickson de mudas de Ixora, em função das diferentes composições de casca de arroz carbonizada.

\begin{tabular}{|c|c|c|c|c|c|c|}
\hline Substratos & MFPA & MFSR & MSPA & MSSR & MST & IQD \\
\hline & & & & -- & & \\
\hline S1 & $0,23 a$ & $0,31 \mathrm{~b}$ & $0,08 a$ & 0,07 a & $0,14 \mathrm{~b}$ & $0,10 \mathrm{~b}$ \\
\hline S2 & $0,25 \mathrm{a}$ & $0,75 b$ & $0,08 a$ & 0,15 a & $0,23 \mathrm{~b}$ & $0,26 \mathrm{~b}$ \\
\hline S3 & $0,37 \mathrm{a}$ & $0,61 b$ & $0,13 \mathrm{a}$ & $0,13 \mathrm{a}$ & $0,26 \mathrm{~b}$ & $0,18 \mathrm{~b}$ \\
\hline S4 & $0,22 \mathrm{a}$ & $0,94 \mathrm{~b}$ & $0,07 a$ & $0,21 \mathrm{a}$ & $0,28 \mathrm{~b}$ & $0,59 a b$ \\
\hline S5 & $0,33 a$ & $1,31 \mathrm{a}$ & 0,11 a & $0,28 \mathrm{a}$ & $0,90 \mathrm{a}$ & $1,11 \mathrm{a}$ \\
\hline CV (\%) & 57,88 & 86,67 & 59,51 & 87,96 & 73,30 & 27,08 \\
\hline
\end{tabular}

Médias seguidas de letras iguais não diferem entre si pelo teste Duncan à $5 \%$ de significância. S - Substratos; S1 - 100\% Areia; S2 - 20\% CAC; S3 - 40\% CAC; S4 - 60\% CAC; S5 - 80\% CAC + 20\% areia; CV: coeficiente de variação; *: Significativo ao nível de $5 \%$ de probabilidade, pelo teste $\mathrm{F}$; ns: não significativo.

As diferentes porcentagens de substratos não apresentaram efeito significativo para as variáveis massa fresca e seca da parte aérea e massa seca sistema radicular. Somente houve efeito significativo para as variáveis massa fresca do sistema radicular, massa seca total e índice de qualidade de Dickson com a utilização de $80 \%$ de CAC + $20 \%$ de areia. O Índice de qualidade de Dickson apresentou qualidade superior, 1,11 , quando se utilizou o substrato S5 ( $80 \%$ de CAC $+20 \%$ de areia), superior em $101 \%$ quando comparado com o substrato sem adição de casca de arroz carbonizada (S1).

\section{DISCUSSÃO}

O resultado encontrado na presente pesquisa referente ao número de folhas contradiz o estudo relatado por Maristela et al. (2019), que não obtiveram efeitos significativos para a variável NF na produção de mudas de alface utilizando substratos formulados a partir de CAC e húmus de minhoca.

A descoberta da presente pesquisa retrata que apesar de um determinado substrato alternativo não 
apresentar influência satisfatória no desenvolvimento de uma variável estudada em uma determinada cultura ele pode ser crucial para outra cultura como demonstra no presente estudo. O resultado de maior desenvolvimento de folhas no substrato $\mathrm{S} 5$ se deu provavelmente devido à qualidade física e química serem suficientes para atenderem as demandas durante a propagação e gerar melhor rendimento de folhas.

Com a extração da gema terminal, ocorre a regeneração da parte aérea da planta, a partir das gemas axilares, mediante a quebra da dominância apical (TAIZ et al., 2012). Segundo Santos et al. (2017), as folhas presentes nas estacas proporcionam a presença de carboidratos e outras biomoléculas, compondo as necessidades dos tecidos, e assim contribuindo com o enraizamento, visto que as folhas são fontes de auxinas, sendo elas translocadas a base da estaca.

A área foliar apresentou maior ocupação espacial com o uso do substrato $80 \%$ CAC $+20 \%$ areia em consequência do aumento do número de folhas que foram encontradas nas mudas produzidas no substrato S5 e, assim, resultando em maior área foliar. Quanto maior a área foliar, maior será a radiação ativa interceptada e o acúmulo de matéria seca (SANQUETTA et al., 2014).

Conforme Campos et al. (2017), ao trabalharem com avaliação do tipo de estaca caulinar e a porção da estaca de $P$. aculeata em substrato alternativo de casca de arroz carbonizada, verificaram que as médias de comprimento das brotações apresentaram-se crescentes, tendo respectivamente os maiores comprimentos as estacas basais, as medianas e as apicais e acrescentaram que este resultado foi semelhante ao obtido por Ferreira et al. (2010), que trabalhando com propagação vegetativa de maniçoba, observaram maior comprimento das brotações em estacas com maior diâmetro. Na presente pesquisa foi utilizada apenas estacas com diferenças mínimas de diâmetro, assim, podendo não ter ocasionado diferença significativa como nos trabalhos citados anteriormente.

A descoberta da presente pesquisa em relação a variável comprimento radicular se enquadra com o encontrado por Kratz et al. (2015) que ao avaliarem a viabilidade técnica da utilização de materiais renováveis e vermiculita como componentes de substratos para produção de mudas de Eucalyptus benthamii x E. dunnii via miniestaquia constataram maior desenvolvimento radicular no substrato composto por casca de arroz carbonizada acrescida a vermiculita.

O volume radicular também apresentou maior rendimento no substrato $80 \%$ de $C A C+20 \%$ de areia. Este resultado obteve bom rendimento assim como a variável comprimento radicular que também apresentou maior rendimento das mudas e, assim, quando colocado na proveta com água fez com que ocorresse maior deslocamento da coluna d'água e consequentemente resultando em maior volume radicular.

Segundo Rota et al. (2008) a adição de CAC favorece a diminuição da densidade e um aumento considerável no espaço de aeração dos substratos, assim, favorecendo o desenvolvimento das raízes. Este fato também pode ser afirmado por Malavolta et al. (1975), no qual afirmam que o oxigênio é necessário para a respiração das raízes, e este é retirado dos interstícios existentes no substrato; portanto, se a aeração for deficiente, por exagerada compactação ou excesso de água, o desenvolvimento radicular fica 
comprometido.

O comprimento e o volume radicular se sobressaíram com o uso do substrato $80 \%$ de CAC $+20 \%$ de areia, provavelmente devido às características físicas e químicas, embora não tenha sido realizada analise física dos substratos na presente pesquisa, é importante acrescentar que quanto mais casca de arroz carbonizada é adicionada a areia mais poroso e menos denso fica o substrato, sendo que promove um maior fluxo de oxigênio.

Este resultado foi em consequência de umas das principais variáveis, massa seca total e massa seca do sistema radicular, apresentarem maior desenvolvimento no substrato S5 e, consequentemente interferirem na qualidade final do IQD. O IQD é apontado como bom indicador de qualidade de mudas porque são utilizados para seu cálculo a robustez e o equilíbrio da distribuição da biomassa (CALDEIRA et al., 2007), ponderando os resultados de várias características morfológicas importantes empregadas para avaliação da qualidade. Quanto maior o IQD, melhor é a qualidade da muda produzida (CALDEIRA et al., 2012).

Diante das descobertas expostas na presente pesquisa é possível destacar que é possível utilizar a casca de arroz carbonizada como substrato alternativo, pois é um importante recurso econômico interessante que apresenta qualidade física e química que além de ser útil para produção de mudas tem como consequência reduzir o custo final que a cada ano só vem aumento e, com essa redução proporcionar mais renda para o agricultor.

\section{CONCLUSÕES}

O uso do substrato alternativo, formulado a base de casca de arroz carbonizada, promove resultados satisfatórios na propagação vegetativa das estacas de Ixora (Ixora coccínea). A palha de arroz carbonizada adicionada à areia proporciona melhorias nas propriedades físicas e químicas do substrato e, consequentemente, favorece a propagação de estacas de ixora, resultando em mudas mais vigorosas e com maior potencial de crescimento e floração no local de interesse. Portanto, recomenda-se o uso na proporção de $80 \%$ de casca de arroz carbonizada mais $20 \%$ de areia para produção de mudas de ixora.

\section{REFERÊNCIAS}

BASSO, C. J.. Épocas de aplicação de nitrogênio para o milho cultivado em sucessão a plantas de cobertura de solo, no sistema plantio direto. Tese (Mestrado em Agronomia) Universidade Federal de Santa Maria, Santa Maria, 1999.

BELLÉ, S.. Apostila de paisagismo. Bento Gonçalves: Instituto Federal de Educação, Ciência e Tecnologia do Rio Grande do Sul, 2013.

CALDEIRA, M. V. W.; DELARMELINA, W. M.; LÜBE, S. G.; GOMES, D. R.; GONÇALVES, E. O.; ALVES, A. F.. Biossólido na composição de substrato para a produção de mudas de Tectona grandis. Revista Floresta, v.42, n.1, p.77-84, 2012. DOI: http://dx.doi.org/10.5380/rf.v42i1.26302

CALDEIRA, M. V. W.; MARCOLIN, M.; MORAES, E.; SCHAADT, S. S.. Influência do resíduo da indústria do algodão na formulação de substrato para produção de mudas de Schinus terebinthifolius Raddi, Archontophoenix alexandrae Wendl. et Drude e Archontophoenix cunninghamiana Wendl. et Drude. Revista Ambiência, v.3, p.1-8, 2007.

CAMPOS, J. A.; OLIVEIRA, N. J. F.; CHAMBA, J. S. V.; COLEN, F.; COSTA, C. A.; SANTOS FILHO, A. S.. Brotação de ora-pronóbis em substrato alternativo de casca de arroz carbonizada. Revista Holos, v.7, p.148-167, 2017. DOI: http://10.15628/holos.2017.6424

CASTRO, V. C.; FERNANDES, M. M.; FERNANDES, M. R. M.; NÓBREGA, R. S. A.. Avaliação de diferentes substratos orgânicos para mudas de Enterolobium contortisiliquum em uma área desertificada. Revista Agrogeoambiental, v.8, n.3, p.101-109, 2016. DOI: http://dx.doi.org/10.18406/23161817v8n32016884 
DI RIENZO, J. A.; CASANOVES, F.; BALZARINI, M. G.; GONZALES, L.; TABLADA, M.; ROBLEDO, C. W.. Infostat version 2011. Buenos Aires: Grupo InFostat, 2011.

DICKSON, A.; LEAF, A. L.; HOSNER, J. F.. Quality appraisal of white spruce and white pine seedling stock in nurseries. The Forestry Chronicle, v.36, p.10-13, 1960. DOI: https://doi.org/10.5558/tfc36010-1

FELICIANA, A. M. C.; MORAIS, E. G.; REIS, E. S.; CORRÊA, R. M.; GONTIJO, A. S.; VAZ, G. H. B.. Influência de auxinas e tamanho de estacas no enraizamento de azaleia (Rhododendron simsii Planch.). Global Science and Technology, v.10, n.1, p.43-50, 2017.

FERREIRA, L. E.; ANDRADE, L. A.; GONÇALVES, G. S.; SOUZA E. P.; FERREIRA H. V.. Diâmetro de estacas e substratos na propagação vegetativa de maniçoba, Manihot glaziovii Muell. Arg. Revista Ciência Agronômica, v.41, n.3, p.393402, 2010.

KOYAMA, R.; ASSIS, A. M.; CARDOSO, C.; MORITZ. A.; ORTIZ, T. A.; ROBERTO, S. R.. Enraizamento de estacas de lichieira tratadas com ácido indolbutírico e substratos. Revista Brasileira de Ciências Agrárias, v.9, n.3, p.384-388, 2014.

KRATZ, D.; PIRES, P. P.; STUEPP, C. A.; WENDLING, I.. Produção de mudas de erva-mate por miniestaquia em substratos renováveis. Floresta, Curitiba, v.45, n.3, p.609616, 2015. DOI: http://dx.doi.org/10.5380/rf.v45i3.36531

MALAVOLTA, E.; ROMERO, J. P.. Manual de adubação. 2 ed. São Paulo: ANDA, 1975.

PASSOS, M. L. V.; ZAMBRZYCKI, G. C.; PEREIRA, R. S.. Balanço hídrico e classificação climática para uma determinada região de Chapadinha-MA. Revista Brasileira de Agricultura Irrigada, v.10, n.4, p.758-766, 2016. DOI: https://10.7127/RBAI.V10N400402

ROTA, L. D.; PAULETTI, G. F.. Efeito da adição de casca de arroz em substrato comercial a base de turfa na produção de mudas de Viola tricolor L. Revista Brasileira Agrociência, v.14, n.3-4, p.45-48, 2008.

SANQUETTA, C. R.; CORTE, A. P. D.; BEHLING, A.; CARDORI, G. C.; COSTA JUNIOR, S.; RUZA, M. S.. Crescimento de área e índice de área foliar de mudas de Eucalyptus dunii Maiden. em diferentes condições de cultivos. Revista Biociências, v.20, n.2, p.82-89, 2014.

SANTOS, M. P.; MARQUES, R. C.; SOUSA, C. M. Enraizamento de estacas caulinares de murta (Murraya exotica L.). Scientific Electronic Archives, v.10, n.2, p.5-10, 2017.

SOUSA, F. X.. Casca de arroz carbonizada: um substrato para propagação de plantas. Lavoura Arrozeira, Porto Alegre, v.46, n.406, p.11, 1993.

STENICO, A. R. P.. Ixora: grande floração torna a planta muito procurada para projetos paisagísticos. Central de Abastecimento de Campinas (CEASA), 2013.

TAIZ, L.; ZEIGER, E.. Fisiologia Vegetal. 5 ed. Porto Alegre: Artmed, 2012.

TRIGUEIRO, R. M.; GUERRINI, I. A.. Utilização de lodo de esgoto na produção de mudas de aroeira-pimenteira. Revista Árvore, v.38, n.4, p.657-665, 2014. DOI: https://doi.org/10.1590/\$0100-67622014000400009

A CBPC - Companhia Brasileira de Produção Científica (CNPJ: 11.221.422/0001-03) detém os direitos materiais desta publicação. Os direitos referem-se à publicação do trabalho em qualquer parte do mundo, incluindo os direitos às renovações, expansões e disseminações da contribuição, bem como outros direitos subsidiários. Todos os trabalhos publicados eletronicamente poderão posteriormente ser publicados em coletâneas impressas sob coordenação da Sustenere Publishing, da Companhia Brasileira de Produção Científica e seus parceiros autorizados. Os (as) autores (as) preservam os direitos autorais, mas não têm permissão para a publicação da contribuição em outro meio, impresso ou digital, em português ou em tradução. 